\title{
An evaluation of health visitors' and social workers' level of knowledge and satisfaction of a local child and family psychiatric service
}

\author{
Aristos Markantonakis, Senior Registrar in Child and Family Psychiatry; and \\ JoHn Mathal, Consultant in Child and Adolescent Psychiatry, The Institute of \\ Family Psychiatry, 23 Henley Road, Ipswich, Suffolk IP1 3TF
}

Although childhood psychiatric disorders are commonly seen in general practice, only a few children in the community gain access to professional help. Whether a child is referred or not depends on various factors to do with the child and family and others, such as what the GP expects from the referral. Severity per se is not the only referral determinant. Whether GPs know what the child psychiatric services in the area have to offer could also be expected to affect referral (Markantonakis \& Mathai, 1990). We are aware of the need for general practitioners to be made more aware of the services that we have to offer.

We attempted to evaluate the level of knowledge and satisfaction with our services from health visitors and social workers in the area of East Suffolk. The service, The Institute of Family Psychiatry, is situated in Ipswich and covers a population of approximately 315,000 in a geographically large and rural area. The Institute has three consultant psychiatrists, two senior registrars and one registrar. There are in addition one and a half clinical psychologists and occupational therapists. The service is dynamically orientated, almost all referrals are medical (from GPs) but the concentration on the family frequently leads to collaboration with other agencies in the community such as health visitors and social workers. The Institute also has an in-patient service for disturbed adolescents based at a different location. The Institute provides the following services: family and marital therapy, individual psychotherapy for children, group psychotherapy for children and adolescents, group therapy for parents, individual psychotherapy for adults. There is no provision for in-patient treatment for disturbed children.

\section{The study}

An anonymous questionnaire was sent to 73 health visitors and 89 social workers in the area of East Suffolk. The questionnaire consisted of six questions requesting a yes or no response.

\section{Findings}

Out of 73 questionnaires sent to health visitors 41 were returned, a response rate of $56 \%$, and out of 89 questionnaires sent to social workers 40 were returned, a response rate of $43 \%$.

\section{(1) Awareness of our service}

Of the health visitors who returned the questionnaire, $93 \%$ were aware that we run courses for them and other professionals; $71 \%$ of the social workers were also aware that we run courses.

(a) Individual psychotherapy for children $95 \%$ of the health visitors and $96 \%$ of social workers were aware that we are providing this service for children.

(b) Group psychotherapy for children $78 \%$ of health visitors and $53 \%$ of social workers were aware that we provide group psychotherapy for children.

(c) Group psychotherapy for parents

$75 \%$ of health visitors and $33 \%$ of social workers were aware that we provide group psychotherapy for parents.

(d) Marital therapy

$41 \%$ of health visitors and $44 \%$ of social workers were aware that we provide marital therapy as a service.

(e) Family therapy

Again here, due to our name 'The Institute of Family Psychiatry', 97\% of health visitors and $96 \%$ of social workers were aware that we provide family therapy to families.

(f) Individual psychotherapy for adults $53 \%$ of health visitors and only $33 \%$ of social workers knew that we provide individual psychotherapy for adults

(g) In-patient unit for disturbed adolescents $59 \%$ of health visitors and $76 \%$ of social workers were aware of the existence of our Adolescent Unit. 
(h) In-patient unit for disturbed children $48 \%$ of health visitors and $64 \%$ of social workers were aware that we do not have a Unit for disturbed children.

\section{(2) Are we accessible?}

Most health visitors (56\%) and social workers $(79 \%)$ felt that we were inaccessible for patients. The most common reasons given were lack of transport facilities, cost of travelling and inconvenience for working parents to attend for appointments. There was a request by social workers $(25 \%)$ for us to hold peripheral clinics and some requested out of hours appointments.

\section{(3) Level of communication}

Most health visitors (65\%) and social workers $(67 \%)$ felt that communication between them and the Institute was good to average, but that communication could be improved by writing more frequently and giving more details in the letters, phoning more and arranging joint meetings and courses for health visitors and social workers.

\section{(4) Patients not accepting referral?}

$60 \%$ of health visitors and $56 \%$ of social workers felt they had experienced significant objections to their clients/patients accepting referrals to the Institute and the most common reasons given were stigma attached to psychiatry and the perception of the name 'Institute' as a threat.

\section{Comments}

We were encouraged by health visitors and social workers feeling that the level of communication between us and them was mostly good to average. However, there is room for improvement and we can see that there is a lack of awareness by both health visitors and social workers about the services we have to offer. Both health visitors and social workers, like GPs, were aware that we provide family therapy for families and again presume that this is due to our title 'The Institute of Family Psychiatry'. Twenty-four per cent of social workers and $41 \%$ of health visitors were unaware of our in-patient unit for disturbed adolescents (compared to $33 \%$ of the GPs). We could understand that health visitors would be less aware of our adolescent unit as they normally deal with the needs of younger children.

Clearly there is a feeling by health visitors and social workers that we need to make ourselves more accessible to patients. As before, travel and cost of travelling were barriers to access and suggestions were made about holding clinics in the peripheries.

Like general practitioners, social workers and health visitors had frequent experience of patients refusing referral to the Institute and, again, the most common reason given was the stigma attached to the label of psychiatry and a finding of the name 'Institute of Family Psychiatry' as threatening. There were some suggestions that we should change our name from Institute to a more 'user friendly' name such as Family and Children's Clinic or Family Therapy Centre.

There is clearly a need to educate the general public as well as professionals as to what psychiatrists do.

\section{Acknowledgements}

We would like to thank Mr Peter Smith and Dr Bill Smith, Consultant in Public Health, for their help in the construction of the questionnaire.

\section{Reference}

Markantonakis, A. \& Mathal, J. (1990) An evaluation of general practitioners' knowledge and satisfaction of a local child and family psychiatric service. Psychiatric Bulletin, 14, 328-329.

A full list of references is available on request to the authors. 